\title{
Measures to Reduce Post Tonsillectomy Pain
}

\author{
Abd El-Hay Rashad Elassy ${ }^{1}$, Ahmed Abd Elhalim Mohamed ${ }^{1}$, Heba Abd Elrehem Abo-Elnaga ${ }^{1}$, \\ Waleed Mahmoud Saleh ${ }^{2}$;
}

ENT Department, Faculty of Medicine, Menoufia Univercity, Menoufia, Egypt

Email address:

waleedsaleh804@yahoo.com (W. M. Saleh)

\section{To cite this article:}

Abd El-Hay Rashad Elassy, Ahmed Abd Elhalim Mohamed, Heba Abd Elrehem Abo-Elnaga, Waleed Mahmoud Saleh. Measures to Reduce Post Tonsillectomy Pain. American Journal of Clinical and Experimental Medicine. Vol. 3, No. 5, 2015, pp. 237-240.

doi: 10.11648/j.ajcem.20150305.17

\begin{abstract}
Objectives: The aim of this study was to review the literature regarding the measures to reduce post tonsillectomy pain. Data sources: They included medical text books, medical journals, and medical websites (PubMed, Medscape, Science Direct and EMF-Portal) and all materials available in the internet from 2000 to 2015. Study selection. The initial search presented 170 articles. The articles studied different tools and techniques in tonsillectomy, pharmacological and non pharmacological methods for reducing post operative pain. Data extraction: Web search was performed on the medical databases and the full text of the relevant paper was critically analyzed and interpreted. Data synthesis: Comparisons were made by a structured review with the results, summarized and incorporated into the review article's main text. Findings: Pain is the most significant obstacle to the rehabilitation of a patient following tonsillectomy. Inadequate analgesia causes poor oral intake, which leads to lassitude, delayed recovery of strength and well being and occasionally requires overnight hospitalization in day case surgical practice. Conclusion: The advances in new surgical tools and techniques make this surgery a safe procedure with less post operative pain. The pain can be managed also in a more effective manner with the combination of pharmacological and non-pharmacological therapies.
\end{abstract}

Keywords: Analgesia, Pain, Techniques, Tonsillectomy

\section{Introduction}

Pain is the most significant obstacle to the rehabilitation of a patient following tonsillectomy. Inadequate analgesia causes poor oral intake, which leads to lassitude, delayed recovery of strength and well being and occasionally requires overnight hospitalization in day case surgical practice. ${ }^{[1]}$

In the light of the problems associated with post-operative pain, various strategies for the management of post tonsillectomy pain have been proposed like the choice of the technique of surgery, tonsillar fossa closure, infiltration of local anesthetic, Application of sucralfate and magnesium sulfate as a protective barrier following tonsillectomy has been found to promote healing with significant pain reduction in the post-operative period. Drugs like nonsteroidal anti-inflammatory (NSAID) narcotics and oral analgesics. Recently encouraging results following use of transcutaneous electric nerve stimulation (TENS) for post tonsillectomy pain has also been reported. ${ }^{[1]}$

\section{Materials and Methods}

\subsection{Search Strategy}

We reviewed papers on different measures and methods to reduce the pain after tonsillectomy operation. The search was performed in the electronic databases from 2000 to 2015.

\subsection{Study Selection}

All the studies were independently assessed for inclusion. They were included if they fulfilled the following criteria:

- Published in English language.

- (Published in peer-reviewed journals.

- Focused on post tonsillectomy pain management and reduction.

- If a study had several publications on certain aspects, we used the latest publication giving the most relevant data. 


\subsection{Data Extraction}

Studies that did not fulfill the above criteria, such as studies on tonsillectomy morbidity other than pain, post tonsillectomy pain but not focus on its management and reduction, reports without peer-review, studies that were not within the national research programme, letters/comments/ editorials/news and studies not focused on post tonsillectomy pain, were excluded.

\subsection{Quality Assessment}

The quality of all the studies was assessed. Important factors included the study design, attainment of ethical approval, and evidence of a power calculation, specified eligibility criteria, appropriate controls, adequate information and specified assessment measures. It was expected that confounding factors would be reported and controlled for and appropriate data analyses made in addition to an explanation of missing data.

\subsection{Data Synthesis}

A structured systematic review with the results summarized and incorporated into the review article's main text.

\section{Discussion}

The main concern after tonsillectomy is post-operative pain, it is a very important and unpleasant feature of tonsillectomy and one of the most obstacles we found postoperative. $^{[2]}$ The reason of pain after tonsillectomy is mechanical or thermal damage of surrounding tissue that results in inflammation, spasm of the exposed pharyngeal muscles and nerve irritation. It has been proposed that the choice of tonsillectomy technique, to prescribe sufficient pain medication and given proper counseling for pain management after discharge to allow a smooth recovery may have significant implications for postoperative pain. ${ }^{[3]}$

So, we can divide the measures for reducing postoperative pain according to the tool used in the surgery, the technique during surgery, systemic medications and nonpharmacological treatment.

There are several techniques for tonsillectomy and their relative effectiveness remains a matter of debate. Each has its advantages and disadvantages and the method chosen by the surgeon has often depended on their personal preference based on training and experience. The techniques of Tonsillectomy can be broadly divided into 2 major categories: extracapsular (total tonsillectomy, subcapsular) and intracapsular (partial tonsillectomy). ${ }^{[4]}$ The existing literature consistently reports that the intracapsular (partial) tonsillectomy either by microdebrider or other techniques result in less postoperative pain and a faster resumption of a normal diet. This favorable course can be attributed to the preservation of the tonsillar capsule and of a thin layer of tonsillar tissue, which can act as a 'biological dressing' to protect the pharyngeal muscle and avoid an inflammatory reaction, which is the main cause of postoperative pain. ${ }^{[5]}$

Table 1. Postoperative pain score in children after microdebrider intracapsular tonsillotomy and traditional tonsillectomy using a visual analogue scale.

\begin{tabular}{llll}
\hline & Microdebrider & T. tonsillectomy & P value \\
\hline 1st day & $2.00 \_1.00$ & $3.75 \_0.50$ & 0.019 \\
2nd day & $1.33 \_1.16$ & $3.25 \_0.50$ & 0.005 \\
3rd day & $0.67 \_1.16$ & $3.00 \_1.16$ & 0.038 \\
\hline
\end{tabular}

The techniques of tonsillectomy can also divided into cold and hot tonsillectomy. Hot dissection, such as electrosurgery, bipolar diathermy and thermal welding has been reported to cause relatively more severe postoperative pain than cold conventional dissection tonsillectomy. As it produces more tissue injuries, which results in increased local edema and inflammation. These disadvantages seem to be caused by the difficulty of controlling the depth of heat coagulation and subsequent devitalization when using diathermy however, the latter procedure is typically faster and has less intraoperative blood loss. ${ }^{[6]}$ So we can say that the cold dissection tonsillectomy is still regarded as the gold standard as it allows maximum preservation of the oral mucosa. The mechanical injury to the oral mucosa is less when compared with thermal injury. ${ }^{[7]}$

Table 2. Postoperative pain score in children after thermal welding, bipolar cautery and traditional tonsillectomy using a visual analogue scale.

\begin{tabular}{lll}
\hline & Cold dissection group & $\begin{array}{l}\text { Bipolar cautery } \\
\text { dissection group }\end{array}$ \\
\hline $\begin{array}{l}\text { Post-operative pain } \\
\text { score by VAS }\end{array}$ & $4.5 \pm 1.2$ & $6.35 \pm 1.2$ \\
\hline
\end{tabular}

There are different techniques can we used to decrease post operative pain we can do it during surgery. One of these techniques is tonsillar fossa closure by sutures; sealing was performed by laying the posterior pillar mucosa over the tonsillar fossa and suturing it with anterior pillar mucosa. It observed that the decrease of post tonsillectomy pain as a result of preventing the irritation of naked nerve endings and supplying more epithelization of tonsillectomy lodges by attaching the anterior and posterior tonsillar arches to each other with a suture. The disadvantages of this procedure are the tissue edema caused by the sutures is more and prolongs the surgical time and so the time passed under anesthesia is longer for the child. ${ }^{[8]}$

Another technique during tonsillectomy is application of local anesthesia either by preincisional peritonsillar infiltration, post-tonsillectomy wound infiltration and posttonsillectomy packing with soaked gauze. The results demonstrate less pain for all patients after application of local anesthesia however the post-tonsillectomy infiltration of the wounds with $0.25 \%$ bupivacaine is superior to pre-incisional infiltration technique as well as post-tonsillectomy packing of the wounds with bupivacaine-soaked gauze swab. ${ }^{[9]}$

Also topical application of magnesium sulfate and sucralfate was beneficial in reduction of pain in the postoperative period but cannot be utilized as a single agent for pain relief in children. It is simple, safe, tolerated, and 
low-cost; it is an important tool as adjuvant treatment of posttonsillectomy pain. ${ }^{[10][11]}$

Advances in new surgical techniques make this surgery a safe procedure with less pain however, postoperative morbidity and in particular the treatment of postoperative pain continues to be a controversial point, with no clear consensus on its ideal treatment. The search for various treatments to decrease postoperative morbidity in tonsillectomy is justifiable. Many therapeutic modalities ranging from analgesics, corticosteroids and antibiotics have been used as effective means for post tonsillectomy pain control in children. ${ }^{[12]}$
There is a wide spectrum of analgesic drugs currently available for post tonsillectomy pain, with significant differences in mode of delivery, efficacy, safety and side effects. The choice of analgesic agents and technique for post-operative use depends on various factors like efficacy, convenience, cost and safety. ${ }^{[13]}$ Paracetamol is the safest analgesic which is definitely a viable alternative to the NSAIDs, especially because of the lower incidence of adverse effects, and should be the preferred choice in highrisk patients. Paracetamol is also recommended because of less bleeding after tonsillectomy. ${ }^{[14]}$

Table 3. Summarizes the doses and routes of administration of frequently used drugs.

\begin{tabular}{|c|c|c|}
\hline & Administration & Dosage \\
\hline \multicolumn{3}{|l|}{ OPIOIDS } \\
\hline Morphine & $\begin{array}{l}\text { (i) Intravenous. } \\
\text { (ii) Subcutaneous by continuous infusion or intermittent } \\
\text { boluses via indwelling cannula. } \\
\text { (iii) Intramuscular (not recommended due to incidence } \\
\text { of pain. 5-10 mg 3-4 hourly). }\end{array}$ & $\begin{array}{l}\text { IV PCA } \\
\text { Bolus: } 1-2 \mathrm{mg} \text {, lockout: } 5-15 \mathrm{~min} \text { (usually } 7-8 \mathrm{~min} \text { ), no background } \\
\text { infusion. } \\
\text { Subcutaneous } \\
0.1-0.15 \mathrm{mg} / \mathrm{kg} 4-6 \text { hourly, adapted in relation to pain score, sedation and } \\
\text { respiratory rate. }\end{array}$ \\
\hline Tramadol & $\begin{array}{l}\text { (i) Intravenous: inject slowly (risk of high incidence of } \\
\text { nausea and vomiting). } \\
\text { (ii) Intramuscular. } \\
\text { (iii) Oral administration as soon as possible. }\end{array}$ & $\begin{array}{l}0.75-1.0 \mathrm{mg} / \mathrm{kg} \\
50-100 \mathrm{mg} 6 \text { hourly. }\end{array}$ \\
\hline \multicolumn{3}{|l|}{ NONOPIOIDS } \\
\hline Paracetamol & $\begin{array}{l}\text { (i) Oral } \\
\text { (ii) Intravenous. }\end{array}$ & $\begin{array}{l}4 \times 1 \mathrm{~g} \text { paracetamol/day. } \\
\text { Dose to be reduced }(\mathrm{e} . \mathrm{g} .3 \times 1 \mathrm{~g} / \text { day }) \text { in case of hepatic insufficiency. } \\
100 \mathrm{ml} \text { solution }(10 \mathrm{mg} / \mathrm{ml}) \text { administration over a period of } 15 \text { minutes. }\end{array}$ \\
\hline $\begin{array}{l}\text { Combination of } \\
\text { paracetamol and } \\
\text { codeine }\end{array}$ & Oral & $\begin{array}{l}\text { Paracetamol } 500 \mathrm{mg}+\text { codeine } 30 \mathrm{mg} \text {. } \\
4 \mathrm{x} 1 \mathrm{~g} \text { paracetamol/day. }\end{array}$ \\
\hline NSAIDs & $\begin{array}{l}\text { (i) Intravenous administration should start at least } 30-60 \\
\text { min before end of surgery. } \\
\text { (ii) Oral administration should start as soon as possible. } \\
\text { Duration: } 3-5 \text { days. } \\
\text { (iii) Rectal }\end{array}$ & $\begin{array}{l}\text { Ketorolac: } 3 \text { x } 30-40 \mathrm{mg} / \text { day (only IV form) } \\
\text { Diclofenac: } 2 \text { x } 75 \mathrm{mg} / \text { day } \\
\text { Ketoprofen: } 4 \text { x } 50 \mathrm{mg} / \text { day } \\
\text { (ii) Selective NSAIDs } \\
\text { include: } \\
\text { Meloxicam } 15 \mathrm{mg} \text { once daily } \\
\text { Celecoxib: } 200 \mathrm{mg} / \text { day. }\end{array}$ \\
\hline
\end{tabular}

The effects of systemic corticosteroids on postoperative morbidity after tonsillectomy have been studied for decades, as this remains a significant clinical problem for the patient as well as physician. Recent studies indicate that of dexamethasone significantly reduces morbidity after tonsillectomy. A single dose of dexamethasone given at the induction of anesthesia reduced the incidence of early and late post operative nausea and vomiting and improved pain scores on the second postoperative day. ${ }^{[14]}$

As regard to antibiotics, some study suggest that postoperative oral antibiotics do not significantly reduce post-tonsillectomy pain but result in an earlier return to normal activity and diet by approximately 1 day. Given the frequency that tonsillectomy is performed, this possible benefit should be weighed against the cost and potential side effects of routine antibiotic therapy. ${ }^{[15]}$

While medical drugs are being used for treating the somatic (physiological and emotional) dimension of the pain, non-pharmacological therapies aim to treat also the affective, cognitive, behavioral and socio-cultural dimensions of the pain. These non pharmacologic techniques, such as honey which decreases the need to analgesics via pain reduction after surgery ${ }^{[16]}$, cold diet which increased the pain threshold and reduce the edema and treat the pain by taking the inflammation process under control and at the same time allow the patient to get fluids in ${ }^{[17]}$, transcutaneous electrical nerve stimulation which help reducing the pain level and dosage of using analgesics by artificial stimulation of nerve fibers which try to stop or reduce the pain transmission ${ }^{[18]}$, relaxing therapy and distraction which increases the tolerance for pain and decrease the sensitivity for pain by getting the attention away from the pain ${ }^{[19]}$ and also acupuncture can be used in an attempt to alleviate postoperative pain. ${ }^{[20]}$

\section{Conclusion}

Post tonsillectomy Pain is the most significant obstacle to the rehabilitation of a patient after. The challenge here is to keep the patient comfort after surgery and decrease his feeling of pain post operative, so many measures developed 
to reach this target for the sake not the patient only but the surgeon also.

The advances in new surgical tools and techniques make this surgery a safe procedure with less pain however, postoperative morbidity and in particular the treatment of postoperative pain continues to be a controversial point, with no clear consensus on its ideal treatment. The search for various treatments to decrease postoperative morbidity in tonsillectomy is justifiable.

As a result, the pain can be managed in a more effective manner with the combination of pharmacological and nonpharmacological therapies.

Many therapeutic modalities ranging from analgesics, corticosteroids and antibiotics have been used as effective means for post tonsillectomy pain control and also the nonpharmacological therapies aim to treat the affective, cognitive, behavioral and socio-cultural dimensions of the pain.

\section{References}

[1] Indian Journal of Otolaryngology and Head and Neck Surgery, POST - TONSILLECTOMY PAIN Vol. 54 No, 2, April - June 2002.

[2] Allford M, Guruswamy V: a national survey of the anesthetic management of tonsillectomy surgery in children. Paediatr Anaesth 2009; 19:145-152.

[3] Solares CA, Koempel JA, Hirose K, Abelson TI, Reilly JS, Cook SP.: Safety and efficacy of powered intracapsular tonsillectomy in children: A multi-center retrospective case series. Int J Pediatr Otorhinolaryngol 2005; 69:21-26.

[4] Schmidt R, Herzog A, Cook S, O'Reilly R, Deutsch E, Reilly J Complications of tonsillectomy: A comparison of techniques. Arch Otolaryngol Head Neck Surg 2007; 133:925-928.

[5] Derkay CS, Darrow DH, Welch C, Sinacori JT. Posttonsillectomy morbidity and quality of life in pediatric patients with obstructive tonsils and adenoid: microdebrider vs electrocautery. Otolaryngol Head Neck Surg 2006; 134:11420 .

[6] Karatzias GT, Lachanas VA, Papouliakos SM, Sandris VG. Tonsillectomy using the thermal welding system.ORL J Otorhinolaryngol Relat Spec 2005: 67:225-9.

[7] Messner HA. Tonsillectomy. Operative Techniques in Otolaryngology. 2005; 16:224-228.
[8] E. Genc, D. Hanci, N. T. Ergin, T. Dal, Can mucosal sealing reduce tonsillectomy pain? Int. J. Pediatr. Otorhinolaryngol. 2006; 70 725-730.

[9] Eur Arch Otorhinolaryngol, Application methods of local anesthetic infiltrations for postoperative pain relief in tonsillectomy: a prospective, randomized, double-blind, clinical trial 2009; 266:1615-1620.

[10] HK J Paediatr (new series) Effect of Postoperative Topical Administration of Magnesium Sulfate on Pain Relief in Pediatric Adenotonsillectomy: A Randomized Controlled Study 2012; 17:109-114.

[11] Ann Eu Med; Topical Sucralfate and Postoperative Pain after Tonsillectomy 2014; 2(3): 17-20.

[12] Bailey BJ, Johnson JT, Newlands SD. Head and neck surgeryotolaryngology. In: Tonsillitis, tonsillectomy, and adenoidectomy. 4th ed. Philadelphia: Lippincott Williams \& Wilkins 2006; p. 1183---98.3.

[13] Wilson ME, Helgadottir HL. Patterns of pain and analgesic use in 3- to 7-year-old children after tonsillectomy. Pain Manag Nurs. 2006; 7(4):159-166.

[14] Vadivelu N, Mitra S, Narayan D (2010). Recent advances in postoperative pain management. Yale J Biol Med, Vol.83, No.1 (Mar), pp.11-25, Review, ISSN 0044-0086.

[15] Kaan MN, Odabasi O, Gezer E, Daldal A. The effect of preoperative dexamethasone on early oral intake, vomiting and pain after tonsillectomy. Int J Pediatr Otorhinolaryngol 2006; 70: 73-9.

[16] Burkhart and Steward, the Journal of Laryngology \& Otology 115: June 2005: Antibiotics for Reduction of Posttonsillectomy Morbidity. Anesth Pain; Post Tonsillectomy Pain can honey reduce the analgesic requirement. 2013; 3.

[17] Saeki, Y. Effect of Local Application of Cold or Heat for Relief of Pricking Pain. Nursing and Health Sciences. 4(3):97105; Sep 2002.

[18] Bjordal, M. J.; Johnson, I. M. \& Ljunggreen, A. E. Transcutaneous Electrical Nerve Stimulation (TENS) Can Reduce Postoperative Analgesic Consumption: A MetaAnalysis with Assesment of Optimal Treatment Parameters for Postoperative Pain. The European Journal of Pain, 2003; 7(2): 181-188.

[19] Kwekkeboom KL \& Gretarsdottir E: Systematic review of relaxation interventions for pain. J Nurs Scholarsh 2006; 38(3): 269-77.

[20] Snyder, M. \& Wieland, J. Complementary and alternative therapies: What is their place in the management of chronic pain? Nurs Clin North Am. 2003: 38(3): 495-508; Sep 2003. 